\title{
Climatically-mediated landcover change: impacts on Brazilian territory
}

\author{
MARINA ZANIN ${ }^{1}$, GEIZIANE TESSAROLO ${ }^{2}$, NATHÁLIA MACHADO ${ }^{2}$ and ANA LUISA M. ALBERNAZ ${ }^{3}$ \\ ${ }^{1}$ Federal University of the Espírito Santo, Center of Natural and Human Sciences, Biology \\ Department, Av. Fernando Ferrari, 514, Goiabeiras, 29075-910 Vitória, ES, Brazil \\ ${ }^{2}$ Ecology Department, Federal University of Goiás, Av. Esperança, s/n, Campus \\ Samambaia, Itatiaia, 74690-900 Goiânia, GO, Brazil \\ ${ }^{3}$ Earth Sciences and Ecology Center, Emílio Goeldi Museum of Pará, Av. \\ Perimetral, 1901, Terra Firme, 66077-830 Belém, PA, Brazil
}

Manuscript received on April 24, 2016; accepted for publication on October 28, 2016

\begin{abstract}
In the face of climate change threats, governments are drawing attention to policies for mitigating its effects on biodiversity. However, the lack of distribution data makes predictions at species level a difficult task, mainly in regions of higher biodiversity. To overcome this problem, we use native landcover as a surrogate biodiversity, because it can represent specialized habitat for species, and investigate the effects of future climate change on Brazilian biomes. We characterize the climatic niches of native landcover and use ecological niche modeling to predict the potential distribution under current and future climate scenarios. Our results highlight expansion of the distribution of open vegetation and the contraction of closed forests. Drier Brazilian biomes, like Caatinga and Cerrado, are predicted to expand their distributions, being the most resistant to climate change impacts. However, these would also be affected by losses of their closed forest enclaves and their habitat-specific or endemic species. Replacement by open vegetation and overall reductions are a considerable risk for closed forest, threatening Amazon and Atlantic forest biomes. Here, we evidence the impacts of climate change on Brazilian biomes, and draw attention to the necessity for management and attenuation plans to guarantee the future of Brazilian biodiversity.
\end{abstract}

Key words: Climate change, Brazil, ecological niche modeling, native landcover, biomes.

\section{INTRODUCTION}

The decline in biodiversity is reaching alarming rates (Pimm et al. 2014) and, among the many drivers, habitat loss, fragmentation, hunting, logging and species invasions have been highlighted (IUCN 2015). In recent years, global anthropogenic climate change has emerged as a

Correspondence to: Marina Zanin

E-mail: marinazaning@gmail.com growing concern among researchers and managers as it threatens biodiversity, and it is being widely discussed in the scientific literature (Bellard et al. 2012, Cahill et al. 2012, Dawson et al. 2011, Stanton et al. 2014). Biodiversity loss usually mirrors other environmental changes, which can compromise ecosystem services such as carbon storage and regulation of water and nutrient cycles. These changes adversely affect the quality of life and the 
potential productivity of land. Thus, understanding the effects of future climate change on biodiversity, and designing efficient conservation strategies to avoid or mitigate it, is one of the primary contemporary challenges of science (Cahill et al. 2012).

Many studies have been conducted to understand the effects of climate change on focal taxa (Forrest et al. 2012), biomes (Faleiro et al. 2013, Lemes et al. 2013), or even globally (Foden et al. 2013). These studies have found different species responses to climate change, such as adaptation to new environmental conditions (Møller et al. 2008), migration or range displacement to more adequate locations (Hickling et al. 2006), and extinctions (Cahill et al. 2012). Although these studies provide useful information about the impacts of climate change on biodiversity, our current knowledge is still insufficient to measure the real consequences of this threat for many species and locations around the world (Heller and Zavaleta 2009).

Given the uncertainty surrounding the consequences of climate change, many countries are trying to predict alterations that could threaten biodiversity and are elaborating mitigation and adaptation plans (Organização das Nações Unidas 2012). However, reliable data on species distributions are unavailable or scarce for most species and regions of the world, complicating evaluations of complete biotas (Rodrigues and Brooks 2007). This lack of data is even more critical in regions of higher biodiversity, including Brazil-a large and mega-diverse country with a high taxonomic and spatial bias on species distribution data (Lewinsohn and Prado 2002) -for which climate change could have catastrophic effects (Marengo 2015).

In this study, to overcome the scarcity of species distribution data, we use native landcover as a surrogate to understand the main environmental alterations mediated by future climate change in Brazil. Native landcover is clearly influenced by climatic conditions, pointing to its potential to be affected by future climate change, as well as to be predicted by climatic variables (Aber and Melillo 2001, Richards 1996). In addition, it can be an adequate biodiversity surrogate, once it can characterize habitat for many species, mainly specialists, and represent different types or levels of ecosystem services (Burkhard et al. 2010, Lombard et al. 2003, Rodrigues and Brooks 2007). In this way, evaluate the impacts of climate change on distribution of native landcover could emerge as an interesting and efficient approach to study climate impacts, generating comparable results throughout the Brazilian territory and with the advantage of being completely free from taxonomical bias.

Here, we describe and quantify the effects of future climate change on the distribution of native landcover in Brazil. We then map the vulnerable areas of the Brazilian territory that need more attention from conservation managers. Finally, we summarize the impacts at a biome level, since climate change affects each of them differently and there are different laws regulating their conservation. To achieve our goals, we use novel and efficient tools to develop a conceptual and methodological framework, in order to guarantee more reliable results and generating information to support conservation policies in Brazil (Figure 1).

\section{MATERIALS AND METHODS}

\section{STUDY AREA AND DATABASE}

Brazil is a mega-diverse country and harbors one of the largest tropical forest refuges of the world (Laurance et al. 2012). It is divided into six biomes: Amazon, Cerrado, Atlantic Forest, Caatinga, Pantanal and Pampas (Figure 2), which have different land uses, human densities and conservation laws. We characterized the Brazilian landcover using the GlobCover map (available at http://due.esrin.esa.int/page_globcover.php). The GlobCover map is coordinated by the European 
Spatial Agency (ESA) and supplies global landcover data at $300 \mathrm{~m}$ resolution (Bontemps et al. 2011). This database classifies the global surface into 22 categories, of which 18 occur in Brazil, but only eight are predominantly composed by native vegetation (Table I). Despite GlobCover being a global landcover classification, its classification is the most recent that is methodologically homogenous throughout our study area.

The climate data used here are 19 variables related to temperature and precipitation available in the WordClim database (for details about climate data, see http://www.worldclim.org/bioclim), regarding both the current climate scenario and climate predictions to the years 2050 and 2070. The current climate scenario consisted of the WorldClim database (Hijmans et al. 2005). For future predictions, we used climate models HadGEM2 ES from the Coupled Model Intercomparison Project - Phase 5 (available at http://www.metoffice. gov.uk/research/modelling-systems/unified- model/climate- models), according two different greenhouse gas emission scenarios, namely the Representative Concentration Pathways (RCP) 4.5 and 8.5. The model RCP 4.5 considers a mediumlow level of gas emissions (optimistic scenario), whereas RCP 8.5 corresponds to high gas emissions (pessimistic scenario). We used this climate model and scenarios because it was selected to the "Third Brazilian Nacional Communication of Climate Changes" and it is the base model of "Climatic Modelling and Sectorial Vulnerabilities of the Climate Changes in Brazil".

We overlaid landcover and climatic variables with $20 \mathrm{~km}$ grid cells, upscaling the averages of climatic variables and the most abundant landcover category. This scale was selected because consisted in the smaller grain adopted by "Third Brazilian Nacional Communication of Climate Changes". We excluded those grid cells classified as an anthropogenic landcover class because the distribution of anthropogenic landcover (urban

\section{TABLE I}

Data on number of locations used in the modelling approach and accuracy statistics for the decision tree classification. The native vegetation categories follow the GlobCover map (available at http://due.esrin.esa.int/page_globcover.php). Total number of grid cells for each native landcover category (TGC), the grid cell number used to aggregate climaticallysimilar cells through the decision tree analysis (DT), the accuracy statistics of the decision tree classification (Kappa and Z statistics), and to predict distribution of the landcover group through ecological niche modelling (ENM) are provided.

\begin{tabular}{|c|c|c|c|c|c|}
\hline Lancover category & TGC & DT & Kappa & $\mathbf{Z}$ & ENM \\
\hline \multicolumn{6}{|l|}{ Closed vegetation } \\
\hline $\begin{array}{l}\text { Closed to open }(>15 \%) \text { broadleaved evergreen and/or semi- } \\
\text { deciduous forest }(>5 \mathrm{~m})\end{array}$ & 9431 & 1415 & 0.73 & $32.12 *$ & 1930 \\
\hline Closed $(>40 \%)$ broadleaved forest regularly flooded - Fresh water & 217 & 33 & 0.00 & 0.00 & \\
\hline $\begin{array}{l}\text { Closed ( }>40 \% \text { ) broadleaved semi-deciduous and/or evergreen } \\
\text { forest regularly flooded - Saline water }\end{array}$ & 10 & 2 & 0.00 & NA & \\
\hline \multicolumn{6}{|l|}{ Open vegetation } \\
\hline Open $(15-40 \%)$ broadleaved deciduous forest $(>5 \mathrm{~m})$ & 23 & 3 & 0.00 & NA & 1042 \\
\hline Mosaic Forest/Shrubland (50-70\%) / Grassland (20-50\%) & 12 & 2 & 0.00 & NA & \\
\hline Closed to open $(>15 \%)$ shrubland $(<5 \mathrm{~m})$ & 2395 & 359 & 0.74 & $32.31 *$ & \\
\hline \multicolumn{6}{|l|}{ Closed to open vegetation on regularly flooded or waterlogged soil } \\
\hline $\begin{array}{l}\text { Closed to open ( }>15 \%) \text { vegetation (grassland, shrubland, woody } \\
\text { vegetation) on regularly flooded or waterlogged soil - Fresh, } \\
\text { brackish or saline water }\end{array}$ & 178 & 27 & 0.58 & $25.29 *$ & 710 \\
\hline \multicolumn{6}{|l|}{ Non-classified } \\
\hline Closed ( $>40 \%$ ) broadleaved deciduous forest $(>5 \mathrm{~m})$ & 283 & 42 & 0.00 & 0.00 & NA \\
\hline
\end{tabular}


areas, agricultural lands, etc.) is strongly influenced by variables other than climatic ones (i.e. political incentives for urban/agricultural development, roads, altitude, and others).

\section{AGGREGATION OF CLIMATICALLY-SIMILAR NATIVE LANDCOVER}

To enable our modeling approach, we classified native landcover according to its ability to be predicted by climatic variables. This evaluation is key to testing if native landcover types are linked to a climatic niche and to identify the variables that characterize them. Therefore, we evaluated similarities among grid cells, creating groups that were climatically homogeneous and that still represented the landcover categories.

To achieve this, we used a decision tree analysis to make clusters of similar grid cells. The decision tree algorithm divides the initial dataset (grid cells) into homogeneous subsets taking into account one variable in each subdivision step (nodes), until homogeneous and indivisible subsets (leaves) remain. The results of this division are displayed graphically in binary tree form and the subsets represent our clusters (Breiman et al. 1984). For each step of the decision tree division process, the correlation of the selected variable (i.e. that one generating the subdivision) with all others is calculated; so, correlated variables are avoided, circumventing the problem of multicollinearity among a large number of variables. The homogeneity of clusters was tested by means of a Gini index, which is the most suitable for categorical data (Breiman et al. 1984). To avoid overfitting of the generated tree, we used 1000 cross-validations to balance prediction accuracy and complexity of the model (Breiman et al. 1984).

We selected randomly $15 \%$ of grid cells to make this evaluation (Figure 1). The landcover categories had different extensions and, consequently, were represented by different numbers of cells in the analysis (Table I). Because some landcover categories presented a low area of extension, they were underrepresented in the sample. However, this was not a problem for our approach as, ultimately, they were aggregated into larger vegetation groups with the most similar characteristics.

To evaluate consistency of landcover category assignment, we estimated the mean probability of each landcover category to be reclassified into other categories. This evaluation permitted us to determine: (i) the native landcover categories with high probability of being correctly predicted, i.e. those showing a higher probability of being assigned into their original landcover categories; (ii) the native landcover categories sharing climatic niches, i.e. those with a higher probability of being assigned into other categories; and (iii) those native landcover categories without a climatic niche, i.e. those assigned into many categories.

Finally, we used a random forest analysis to evaluate the importance of climatic variables in the decision tree results. This analysis consisted of 1000 random decision trees constructed through bootstrap sampling and removing one climatic variable at each step (Breiman 2001). By comparing the resulting accuracy of all models, we could assess the relative importance of each predictor variable on the variation of the response variable (Cutler et al. 2007). All analyses were conducted using the R software, with the rpart (Therneau et al. 2011) and random forest packages (Liaw and Wiener 2002).

\section{ECOLOGICAL NICHE MODELING APPROACH}

We used ecological niche modeling (ENM) to estimate the geographic distribution of Brazilian native landcover (Figure 1). This method is commonly used to evaluate the consequences of climate change on species (Elith and Leathwick 2009). Currently, many ecological niche modeling algorithms are available and their predictions can vary greatly due to differences in their analytical 

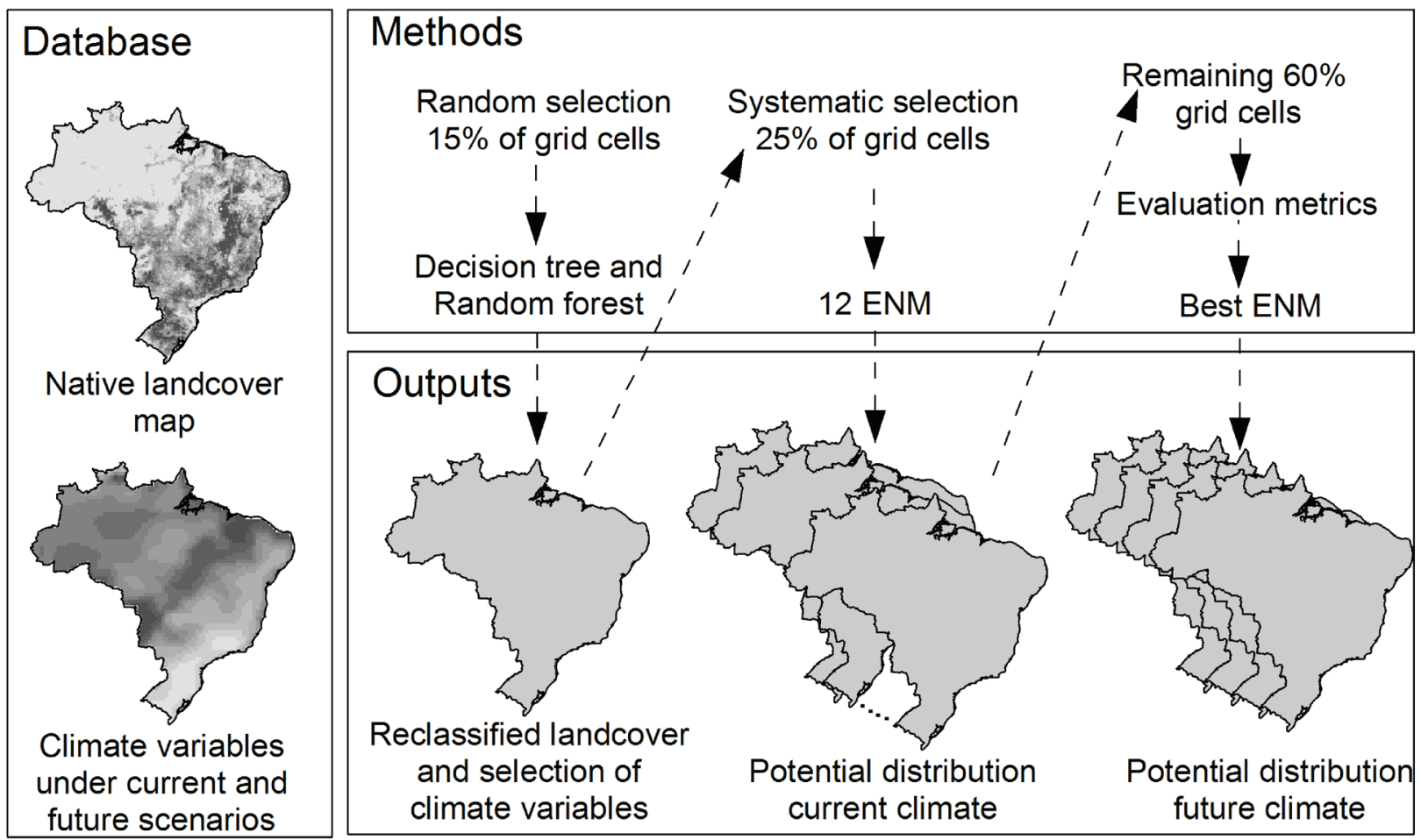

Figure 1 - Schematic approach applied in this study to understand the main environmental alterations under Brazilian biomes mediated by future climate change.

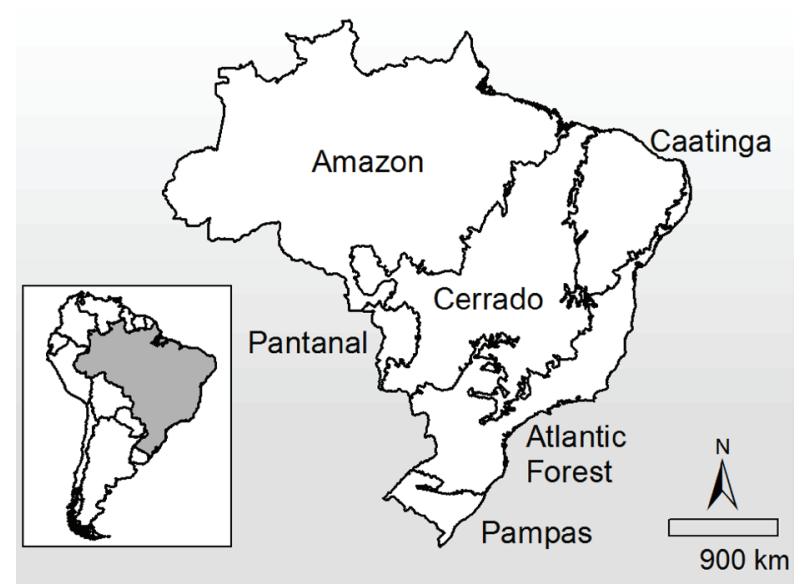

Figure 2 - Study area, comprising Brazil and its biomes.

approach (Araújo and New 2007). ENM can be divided into three general categories (bioclimatic envelope or distance models, statistical models, and machine-learning models), which vary according to complexity, generality and precision (for a review of the main methods, see Araújo and New 2007, Elith and Leathwick 2009, Rangel and Loyola 2012). To deal with the problem of prediction variation amongst models, many researchers consider areas of convergence among models, called ensemble forecasting, as the most probable distribution (Araújo and New 2007, Diniz-Filho et al. 2009).

To estimate the future native landcover distribution, we started our approach by making an exploratory analysis to identify the method that best estimates the current distribution of landcover types. We selected nine ENM techniques, consisting of a variety of methods and concepts, and combined them into three groups from which were generated ensemble forecasting predictions: (i) bioclimatic envelope and distance-based models - BIOCLIM (Busby 1991), Gower distance (Carpenter et al. 1993), Mahalanobis distance (Farber and Kadmon 2003), and ensemble forecasting of bioclimatic envelope and distance models; (ii) statistical models - Generalized Linear Models (GLM; McCullagh and Nelder 1989), Generalized Additive Models (GAM; Hastie and Tibshirani 1990), Multivariate Adaptive Regression Splines (MARS; Friedman 1991), and 
ensemble forecasting of statistical models; and (iii) machine-learning models - Maximum Entropy (MaxEnt; Phillips et al. 2006), Genetic Algorithm for Rule Set Production (GARP; Stockwell and Peters 1999), random forest (Breiman 2001), and ensemble forecasting of machine learning. The ensemble consensuses were generated by a mean of all single-models for each group considered.

To make predictions about the spatial distribution of native landcover based on the current climate scenario, we used $25 \%$ of the grid cells through a systematic sampling that excluded data used in the decision tree analysis (Figure 1; Table I). Systematic sampling has shown good results in ENM selection because it permits biasfree and proportionate sampling of the entire variability of environmental variables, increasing the accuracy of the adjustment curves generated by models (Tessarolo et al. 2014). We divided the $25 \%$ of sampled grid cells into calibration $(75 \%)$ and validation (25\%), and the final distribution of each method was based on 10 replicates of crossvalidation. The threshold applied to convert the occurrence probabilities into binary classification was the prevalence in each data calibration (Nenzén and Araújo 2011). The ensemble forecasting was generated through an average of model predictions weighted by the True Skill Statistics (TSS; Allouche et al. 2006) calculated according to internal validation. The ENMs were generated with the BIOENSEMBLE platform for computerintensive ensemble forecasting (Diniz-Filho et al. 2009).

The variables used to predict the landcover were those identified in the cluster analysis step as being efficient to discriminate climatically unique landcover categories (previous section). We chose to use these selected variables because, in this way, we could increase the robustness of predicted distributions by reducing the number of variables and thereby avoid model overfitting.
The potential distributions generated by ENM of current climate scenario was compared with reference distributions (the landcover categories reclassified according to our decision tree results) using the $60 \%$ of remaining grid cells (i.e. those cells not used in decision tree and landcover modeling for the current climate scenario), as an external validation enabling the selection of the best method. The comparison between the predicted and reference distributions was done through four evaluation metrics: sensitivity, specificity, TSS and Area Under ROC Curve (AUC). The modeling methods with values $>0.8$ in at least three evaluation metrics where considered adequate to be used in the distribution modeling. After choosing the best modeling method, we estimated the distribution of native landcover under future climate scenarios using the same approach previously described for current climate scenario.

\section{RESULTS AND DISCUSSION}

\section{NATIVE LANDCOVER AND CLIMATIC NICHE SIMILARITIES}

Native landcover was efficiently classified by the decision tree (Kappa statistic $=0.69 ; \mathrm{p}<0.001$, percentage of grid cells correctly classified $=$ $88.63 \%$ ), showing that native landcover can be predicted by climatic variables (Figure 3 ). The decision tree was composed of 11 nodes, generated by eight variables, and classified the landcover into three categories (Figure 3 ).

The variables most appropriate for describing landcover categories were isothermality, minimum temperature of the coldest month, mean temperature of the wettest quarter, annual precipitation, precipitation of the wettest month, precipitation of the wettest quarter, precipitation of the driest quarter, and precipitation of the coldest quarter. Thus, this set of variables was used to model landcover under all climate scenarios. 
a

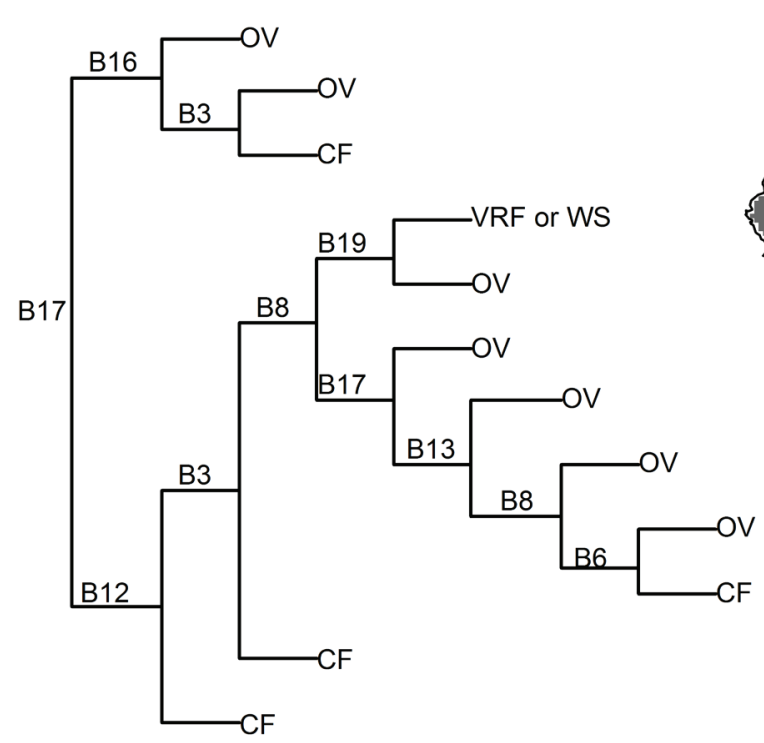

b

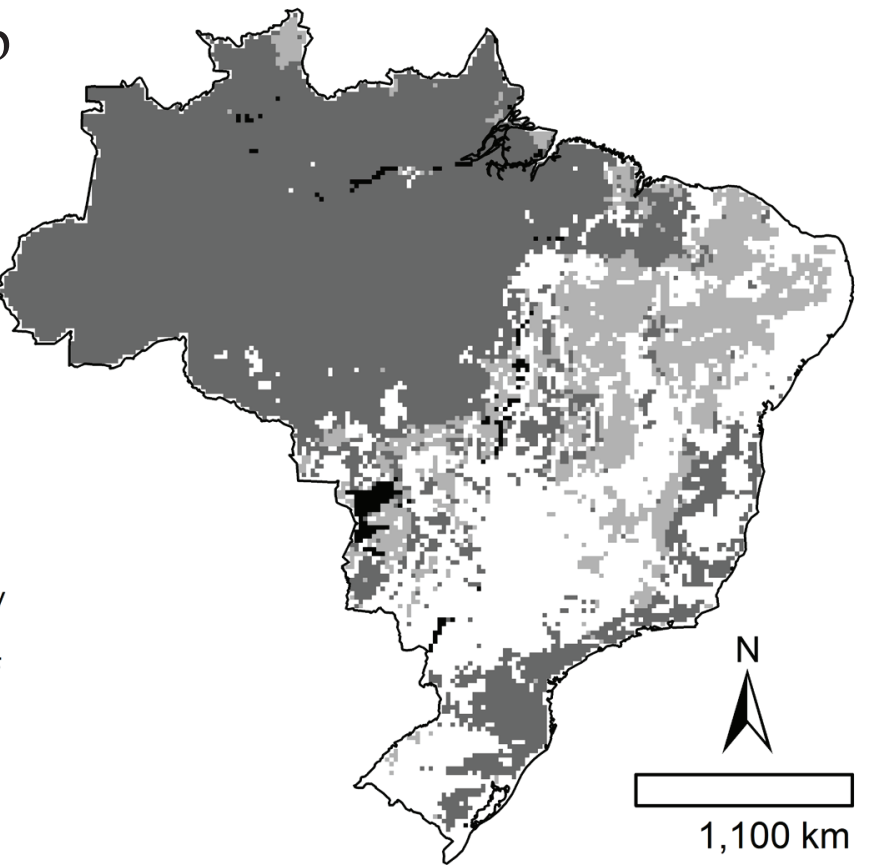

Figure 3 - Current classification of Brazilian landcover. (a) Decision tree analysis, highlighting the variables used to generate the results (B3 - Isothermality, B6 - Min. temperature of coldest month, B8 - Mean temperature of wettest quarter, B12 - Annual precipitation, B13 - Precipitation of wettest month, B16 - Precipitation of wettest quarter , B17 - Precipitation of driest quarter, and $\mathrm{B} 19$ - Precipitation of coldest quarter) and the native landcover predicted to final nodes (OV - Open vegetation, $\mathrm{CF}-\mathrm{Closed}$ forest, and VRF or WS - closed to open vegetation on regularly flooded or waterlogged soil). (b) The reclassified Brazilian landcover according to climatic similarity, where light gray is closed to open shrubland, dark-gray is closed to open broadleaved evergreen and/or semi-deciduous forest, and black is closed to open vegetation on regularly flooded or waterlogged soil, white areas are locations under anthropogenic use and were not evaluated here.

The decision tree identified three categories of landcover: (i) closed to open broadleaved evergreen and/or semi-deciduous forest, (ii) closed to open shrubland, and (iii) closed to open vegetation on regularly flooded or waterlogged soil. Therefore, native landcover categories were aggregated into these three categories because they shared a climatic niche. However, the kappa and $\mathrm{Z}$ statistics showed adequate accuracy for the native landcover classification for closed to open broadleaved evergreen and/or semi-deciduous forest and closed to open shrubland, whilst also revealing the unsuitability of the group closed to open vegetation on regularly flooded or waterlogged soil for study.

Through the mean classification probability, we identified the aggregated native landcovers as follows (Supplementary Material - Figure S1): 1)
The closed broadleaved forest regularly flooded and closed broadleaved semi-deciduous and/or evergreen forest regularly flooded were frequently classified as closed to open broadleaved evergreen and/or semi-deciduous forest, making these a unique climatic group. Due to the forested nature of all categories, we termed this major category as 'closed forest'; 2) the second group was composed of closed to open shrubland, open broadleaved deciduous forest, and mosaic forest/shrubland/ grassland, which we termed 'open vegetation'; and 3 ) the third classified group was the closed to open vegetation on regularly flooded or waterlogged soil, which did not share a climatic niche with any other category due to climatic particularities of this landcover category, which limits our conclusions about it. 
The problem of the third classified group is the extension of its distribution because the total area of closed to open vegetation on regularly flooded or waterlogged soil is only $1 \%$ of the study area (compared to $56 \%$ of closed forest and $14 \%$ of open vegetation). Therefore, closed to open vegetation on regularly flooded or waterlogged soil is underrepresented compared with the other categories. Since this bias could impact the interpretation and conclusions of our study, this group was not considered in subsequent results. In addition, the category closed broadleaved deciduous forest was equally classified into both closed forest and open vegetation groups (Figure S1), lacking a defined climatic individuality, so this landcover type was removed from our analysis.

Although eight native landcover classes are recognized in Brazil according to the GlobCover map, our study reduced this variability to only two climatically-recognized categories: closed forest and open vegetation. This simplification was the result of the large spatial extent of these two landcover categories, which cover broad climatic variability, while the other classes are sparsely distributed over the Brazilian territory. Therefore, we suggest that the native landcover categories with lower geographical extents and that are sparsely distributed should be studied using another sampling design, perhaps with a smaller grid scale. In addition, their distributions probably could be better predicted by including topographic and edaphic conditions, instead of solely climatic variables.

\section{ENM SELECTION AND ACCURACY}

We performed 240 models of native landcover distribution under current climate scenario (12 modeling methods*10 replicas*2 landcover categories), which generated 24 estimated distributions. However, many of them were inconsistent with original distributions, showing that ENM can fail to estimate geographical distributions. The MaxEnt method demonstrated the best performance, being the only one to present values $>0.8$ for three of the evaluation metrics (Figure S2).

ENMs differed in their ability to relate the known spatial distribution of features (geographical coordinates of occurrence) and environmental variables, but machine learning methods are expected to show the best adjustment (Elith and Leathwick 2009, Tsoar et al. 2007). MaxEnt, based on a maximum entropy approach, is frequently used in ENM studies because it produces efficient predictions. The robustness of MaxEnt compared to ensemble forecasting was surprising here, but it is now the most recommended approach in recent studies (Marmion et al. 2009, Tessarolo et al. 2014). However, ensemble forecasting is responsive to low performance models because its accuracy relies on the quality of each individual model. Moreover, ensemble forecasting predictions underestimated distributions, which probably lead to omission errors and, consequently, affected the efficiency of this approach. Therefore, we selected MaxEnt to predict closed forest and open vegetation distributions under future climate scenarios.

In contrast to species distributions, landcover types should not overlap because they do not cooccur. Therefore, we considered as uncertain those locations where distributions of closed forest and open vegetation overlap under the same climatic scenario. The total area of uncertainty was small given the scale of this study, ranging from 1.8-5\% of the Brazilian territory. Distributional uncertainty is common in studies using ENM (Tessarolo et al. 2014), but lower rates of uncertainty, such as observed here, increase the reliability of inferences from both statistical and biological viewpoints. Most areas where models revealed uncertainty are those in transition zones between different landcover categories, such as open and closed forests. Some of these areas currently present a mosaic of closed 
and open vegetation patches, helping to explain the overlap. In the Brazilian Amazon map of vegetation produced by the RADAMBRASIL (Brasil 1978), for example, many of these areas are classified as contact or transition zones.

\section{LANDCOVER CHANGES MEDIATED BY FUTURE CLIMATE SCENARIOS}

The comparison between current and future predicted distributions shows that the range of closed forest will likely be reduced (Figure $4 \mathrm{a})$, threatening the biodiversity it harbors. This impact intensifies according to time and emission scenario, potentially leading to a reduction of about $50 \%$ in the original distribution of closed forest in the country (Figure 4b). The loss of closed forest would occur mainly in the north and west of its current distribution. However, we note that although an overall reduction in closed forest is the general pattern observed for Brazil, regional patterns could be different, such as in southern Brazil where the closed forest prediction revealed a minor expansion (Figure 4a). In contrast, the open vegetation seems to expand its range distribution mainly in the north and west of Brazil, probably replacing the areas lost by closed forest (Figure 4a). This potential expansion also intensifies with time and emission scenarios (Figure $4 b$ ).

A large proportion of areas with potential range expansion, such as southern Brazil and the Amazonian frontiers, are suffering intense anthropogenic influences (Faleiro et al. 2013, Fearnside 2015, Ribeiro et al. 2009). In addition, there is a relatively high human population density in southern Brazil and few native vegetation patches, which gives rise to conservation conflicts. Therefore, the predicted range expansion of closed areas will be faced with anthropogenic barriers and are not actually likely to occur.

Moreover, our predicted expansion could encounter another barrier, i.e. the temporal scale needed for adaptation, considering that we study the near future (2050 and 2070). The intensity and velocity of predicted anthropogenic changes would render adaptive evolution impossible or even prevent species dispersal to adequate areas (Parmesan 2006).

We mapped the most vulnerable locations of Brazil from the climatic instability perspective. These sites are those where the current native landcover is not predicted to occur under future scenarios and, consequently, are susceptible to landcover replacement in the future (Figure 5). The vulnerability areas were generated mainly due to reductions in closed vegetation and potential replacement by open vegetation. Therefore, these areas need attention from a conservation point of view because the negative consequences of climate change on biodiversity in those locations must be mitigated.

BRAZILIAN BIOMES IN THE CONTEXT OF FUTURE CLIMATE CHANGE

Brazilian biomes are likely to respond differently to climate change impacts. The Amazon and Atlantic forests seem to be the most affected because they are strongly represented by closed forest, the distribution of which is predicted to be reduced. The Amazon biome showed heterogeneous impacts across its distribution. The western Brazilian Amazon is the largest stable continuous area through the timeframe examined here, so it suffers lower climate change pressure (Figure 4), contrasting with a large proportion of vulnerable areas in the eastern distribution of Amazon Forest. The total vulnerable areas cover $35-60 \%$ of biome extent according to climate scenarios.

A recent study showed that range-edge populations of trees from the Amazon have more climate plasticity and are the most probable to persist under climate changes (Rehm et al. 2015). The range contractions are predicted to occur from the middle-eastern edge of the Amazon to its core area, which mirrors exactly the direction of the 

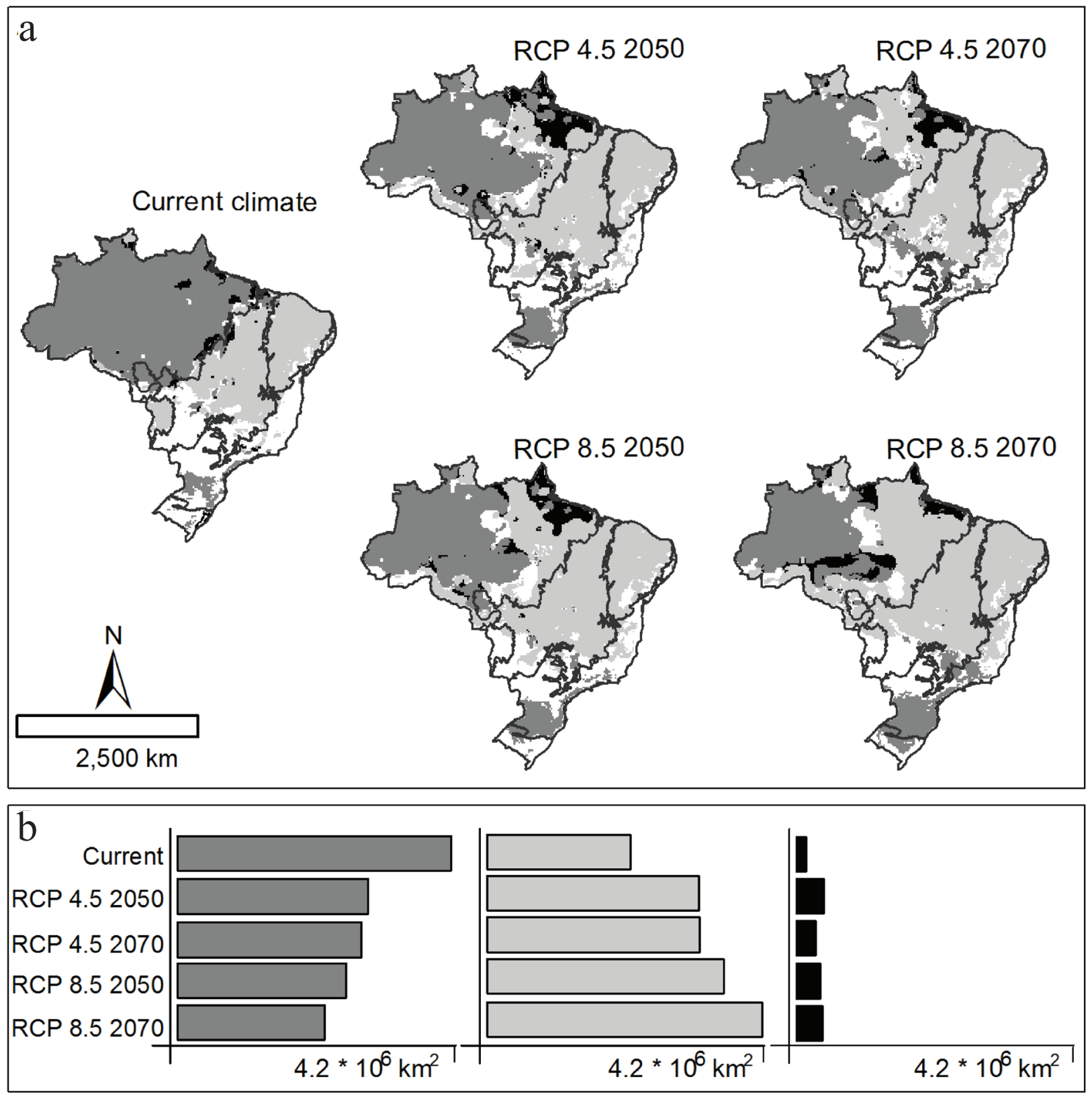

Figure 4 - Current and projected Brazilian native landcovers by category, climatic scenarios and time horizons: (a) spatial distribution and (b) area. Dark-gray represents closed forest, light gray is open vegetation, and black is the uncertainty of model distributions (i.e. locations where both landcovers overlap). In the maps in (a), white areas are locations under anthropogenic use and were not evaluated here.

deforestation arc (i.e. the Brazilian Amazonian region with one of the highest rates of tropical deforestation in the world, largely due to unplanned clearing for pastureland; see Fearnside et al. 2009). Therefore, the habitat conversion occurring in the deforestation arc may be extirpating populations of species better adapted to spatial shifts, increasing the probability of species extinction in the face of rapid future climate change (Rehm et al. 2015). Consequently, losses of the Brazilian Amazon can be profound and probably irreversible without immediate attenuation and management actions. 

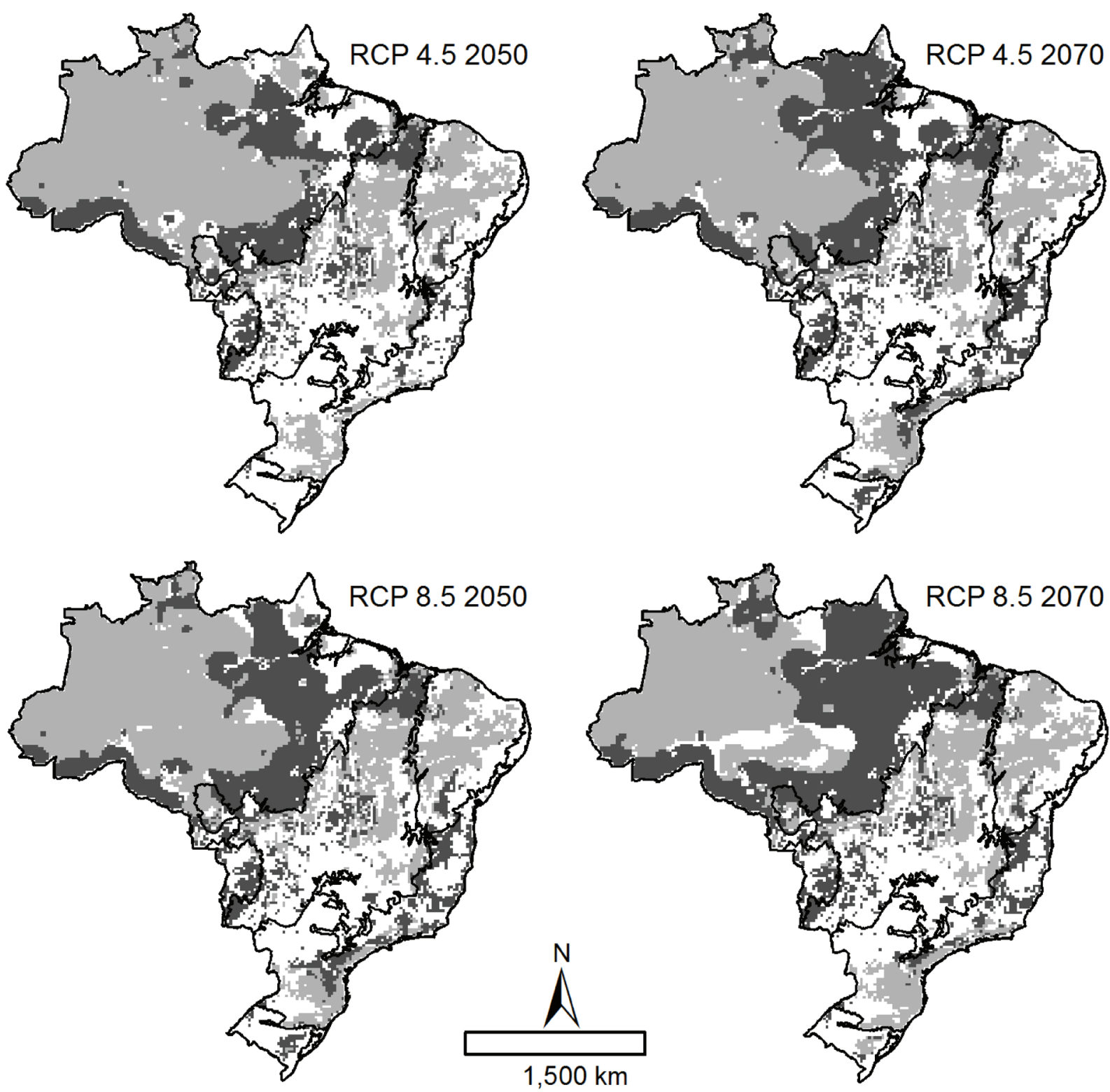

Figure 5 - Future landcover categories and vulnerability sites. Vulnerability sites are those where current landcover is not predicted to occur in future climate scenarios (dark gray). Locations of climatic stability (where current landcover is predicted to occur in future climate scenarios) are represented by light gray. White areas are those under anthropogenic use and were not evaluated here.

The Atlantic Forest presented approximately $115,000 \mathrm{~km}^{2}$ of stable areas located mainly in the south of the biome; this is less than $0.5 \%$ of the total stable area and less than $1 \%$ of the biome's area. It represents the biome with the smallest proportion of stable native landcover and probably the most threatened by climate change. Our results contrast with patterns predicted for past climate change (i.e. glacials and interglacials) for this biome when the biome probably maintained its general geographical position and expanded northwards, suppressing the Cerrado and Caatinga and merged with the Amazon (Ledru et al. 2015, Carnaval and Moritz 2008). Therefore, the potential losses of regional biodiversity of Atlantic Forest can be worse than suggested from past climate change. 
According to studies of past climate change, the Atlantic Forest can respond to climate changes through reorganization of species assemblages, broad spatial shifts and adaptation to restricted areas (Ledru et al. 2015). However, future climate change is likely to differ from those events of the past mainly in terms of the velocity of changes, which conceivably will be too fast to allow adaptive evolution (Parmesan 2006). Moreover, the Atlantic Forest is the most fragmented Brazilian biome, leading to dispersal barriers (Ribeiro et al. 2009) that will limit species range expansion and reorganization of species assemblages. So, even the predicted expansion of closed vegetation in the southern biome might not benefit Atlantic Forest conservation, except if adequate management strategies are adopted. One possible strategy is the restoration of native landcover in areas of climatic stability or future expansion, which could represent a conservation opportunity with the greatest chance of success.

The Cerrado and Caatinga predominantly comprises open vegetation, which seems to be stable under future climate scenarios, so these biomes are likely of lower concern regarding future climate change. Our analysis predicted expansion of open vegetation, mainly of the Cerrado, and that this expansion would occur along the frontier of the Cerrado and Amazon biomes, which corresponds to the deforestation arc. Therefore, as for the Atlantic Forest, the predicted expansion might not occur. These results are somewhat contradictory to those based on projections of the distribution of tree species for the Cerrado (Siqueira and Peterson 2003), which predict a strong contraction for the ranges of such species. It is not possible to know if this discrepancy is due to methodological differences among studies, such as modeling algorithm and climate models. Alternatively, the dry Brazilian biomes could also be threatened by loss of their closed forest enclaves (Figure 4), becoming even more open and losing many of their trees. Despite not being the predominant vegetation type in these biomes, we stress that these closed forest enclaves may harbor habitat-specific or endemic species that do not occur in the open vegetation. Also, many of these enclaves correspond to riparian forests, which are essential to maintaining water sources and to the functioning of natural and productive systems.

The Pantanal and Pampas biomes were not well characterized in our analysis by closed forest or open vegetation, making interpretation of future climate change impacts problematic. These biomes are small compared to others, showing restricted landcover types and differing climate regimes. Thus, a different study approach is necessary to make inferences about these biomes, taking into account more local to regional landcover types and climatic variation, which were not considered in our study.

We found negative consequences of climate change in four of six Brazilian biomes, reinforcing that future climate change is a real threat to Brazilian biodiversity and ecosystems. Climate change can act synergistically with many other anthropogenic impacts, exacerbating its negative consequences for biodiversity (Mantyka-Pringle et al. 2012). Forecasting the future impacts of climate change provides us with important clues about the appropriate conservation strategies needed to mitigate them. Thus, our results provide useful information about the consequences of climate change for Brazilian biomes, allowing the Brazilian government to develop ecological and economically-efficient conservation strategies.

\section{ACKNOWLEDGMENTS}

This study was supported by the Brazilian Minister of Science, Technology, and Innovation through Rede Clima and the Development Project of the Third Brazilian Communication to the United Nations Convention about Climate Changes. 
MZ was supported by Conselho Nacional de Desenvolvimento Científico e Tecnológico (CNPq) DTI-A fellowship number $81738 / 2015-9$ and is currently supported by CNPq DCR fellowship number $312627 / 2015-7$. GT is supported by CNPq PDJ fellowship number 150351/2015-1.

\section{REFERENCES}

ABER JD AND MELILLO JM. 2001. Terrestrial Ecosystems. Pacific Grove: Brooks/Cole Publishing, $2^{\text {nd }}$ ed., $556 \mathrm{p}$.

ALLOUCHE O, TSOAR A AND KADMON R. 2006. Assessing the accuracy of species distribution models: prevalence, kappa and the true skill statistic (TSS). J Appl Ecol 43: 1223-1232.

ARAÚJO MB AND NEW M. 2007. Ensemble forecasting of species distributions. Trends Ecol Evol 22(1): 42-47.

BELLARD C, BERTELSMEIER C, LEADLEY P, THUILLER W AND COURCHAMP F. 2012. Impacts of climate change on the future of biodiversity. Ecol Lett 15: 365-377.

BONTEMPS S, DEFOURNY P, VAN BOGAERT E, KALOGIROU V AND PEREZ JR. 2011. GLOBCOVER 2009. UCLouvain \& ESA Team, Report, 53 p.

BRASIL. 1978. Geologia, geomorfologia, pedologia, vegetação e uso potencial da terra. Departamento Nacional de Produção Mineral. Projeto RADAMBRASIL 1: 34.

BREIMAN L. 2001. Random forest. Computer program.

BREIMAN L, FRIEDMAN J, STONE CJ AND OLSHEN RA. 1984. Classification and Regression Trees. Washington DC: Chapman \& Hall/CRC, p. 368

BURKHARD B, KROLL F AND MÜLLER F. 2010. Landscapes' capacities to provide ecosystem services - a concept for land-cover based assessments. Landsc Online 15: $1-22$.

BUSBY JR. 1991. BIOCLIM - A bioclimatic analysis and prediction system. In Nature Conservation: Cost Effective Biological Surveys and Data Analysis, eds. CR Margules and MP Austin. Canberra: CSIRO, p. 64-68.

CAHILL AE ET AL. 2012. How does climate change cause extinction? Proc Royal Soc B: Biol Sciences 280: e20121890

CARNAVAL AC AND MORITZ C. 2008.Historical climate modelling predicts patterns of current biodiversity in the Brazilian Atlantic forest. J Biogeogr 35: 1187-1201.

CARPENTER G, GILLISON AN AND WINTER J. 1993. DOMAIN: a flexible modelling procedure for mapping potential distributions of plants and animals. Biodivers Conserv 680(2): 667-680.

CUTLER DR ET AL. 2007. Random forests for classification in ecology. Ecology 88(11): 2783-2792.
DAWSON T, JACKSON S AND HOUSE J. 2011. Beyond predictions: biodiversity conservation in a changing climate. Science 332: 53-58.

DINIZ-FILHO JAF ET AL. 2009. Partitioning and mapping uncertainties in ensembles of forecasts of species turnover under climate change. Ecography 32: 897-906.

ELITH J AND LEATHWICK JR. 2009. Species distribution models: ecological explanation and prediction across space and time. Annu Rev Ecol Evol Syst 40: 677-697.

FALEIRO FV, MACHADO RB AND LOYOLA RD. 2013. Defining spatial conservation priorities in the face of landuse and climate change. Biol Conserv 158: 248-257.

FARBER O AND KADMON R. 2003. Assessment of alternati $\mathrm{v}$ e approaches for bioclimatic modeling with special emphasis on the Mahalanobis distance. Ecol Modell 160: 115-130.

FEARNSIDE PM. 2015. Deforestation soars in the Amazon. Nature 521(32): 423.

FEARNSIDE PM ET AL. 2009. Biomass and greenhousegas emissions from land-use change in Brazil's Amazonian "arc of deforestation": the states of Mato Grosso and Rondônia. For Ecol Manage 258: 1968-1978.

FODEN WB ET AL. 2013. Identifying the world's most climate change vulnerable species: a systematic trait-based assessment of all birds, amphibians and corals. PLoS One 8: e65427.

FORREST JL ET AL. 2012. Conservation and climate change: assessing the vulnerability of snow leopard habitat to treeline shift in the Himalaya. Biol Conserv 150: 129135.

FRIEDMAN J. 1991. Multivariate adaptive regression splines. Ann Sta 19: 1-141.

HASTIE TJ AND TIBSHIRANI RJ. 1990. Generalized Additive Models. Chapman \& Hall/CRC.

HELLER NE AND ZAVALETA ES. 2009. Biodiversity management in the face of climate change: a review of 22 years of recommendations. Biol Conserv 142: 14-32.

HICKLING R, ROY DB, HILL JK, FOX R AND THOMAS CD. 2006. The distributions of a wide range of taxonomic groups are expanding polewards. Glob Chang Biol 12: 450-455.

HIJMANS RJ, CAMERON SE, PARRA JL, JONES PG AND JARVIS A. 2005. Very high resolution interpolated climate surfaces for global land areas. Int J Climatol 25: 1965-1978.

IUCN. 2015. The IUCN red list of threatened species. http:// www.iucnredlist.org/. Accessed in July, 2015.

LAURANCE WF ET AL. 2012. Averting biodiversity collapse in tropical forest protected areas. Nature 489 : 290-294.

LEDRU M ET AL. 2015. Long-term spatial changes in the distribution of the Brazilian Atlantic Forest. Biotropica 48: 159-169. 
LEMES P, MELO AS AND LOYOLA RD. 2013. Climate change threatens protected areas of the Atlantic Forest. Biodivers Conserv 23: 357-368.

LEWINSOHN TM AND PRADO PI. 2002. Biodiversidade Brasileira: Síntese Do Estado Atual Do Conhecimento. Brasília: Editora Contexto, p. 176.

LIAW A AND WIENER M. 2002. Classification and regression by randomForest. R News 2: 18-22.

LOMBARD AT, COWLING RM, PRESSEY RL AND AG REBELO. 2003. Effectiveness of land classes as surrogates for species in conservation planning for the Cape Floristic Region. Biol Conserv 112: 45-62.

MANTYKA-PRINGLE CS, MARTIN TG AND RHODES JR. 2012. Interactions between climate and habitat loss effects on biodiversity: a systematic review and metaanalysis. Glob Chang Biol 18: 1239-1252.

MARENGO JA. 2015. Mudanças de clima e os seus impactos no Brasil. Brasília em Debate 1: 24.

MARMION M, PARVIAINEN M, LUOTO M, HEIKKINEN RK AND THUILLER W. 2009. Evaluation of consensus methods in predictive species distribution modelling. Divers Distrib 15: 59-69.

MCCULLAGH P AND NELDER JA. 1989. Generalized Linear Models. Boston, MA. Springer US, $2^{\text {nd }}$ ed., p. 523.

MØLLER A, RUBOLINI D AND LEHIKOINEN E. 2008. Populations of migratory bird species that did not show a phenological response to climate change are declining. PNAS 105: 16195-16200.

NENZÉN HK AND ARAÚJO MB. 2011. Choice of threshold alters projections of species range shifts under climate change. Ecol Modell 222: 3346-3354.

ORGANIZAÇÃO DAS NAÇÕES UNIDAS. 2012. O futuro que queremos. Rio+20 Conferência Das Nações Unidas Sobre Desenvolv. Sustentável, p. 1-21. Rio de Janeiro, Brasil: Organização das Nações Unidas.

PARMESAN C. 2006. Ecological and evolutionary responses to recent climate change. Annu Rev Ecol Evo Syst 37: 637-669.

PHILLIPS SJ, ANDERSON RP AND SCHAPIRE RE. 2006. Maximum entropy modeling of species geographic distributions. Ecol Modell 190: 231-259.
PIMM SL ET AL. 2014. The biodiversity of species and their rates of extinction, distribution, and protection. Science 344: 1246752.

RANGEL TF AND LOYOLA RD. 2012. Labeling ecological niche models. Nat Conserv 10: 119-126.

REHM EM, OLIVAS P, STROUD J AND FEELEY KJ. 2015. Losing your edge: Climate change and the conservation value of range-edge populations. Ecol Evol 5: 4315-4326.

RIBEIRO MC, METZGER JP, MARTENSEN AC, PONZONI FJ AND HIROTA MM. 2009. The Brazilian Atlantic Forest: how much is left, and how is the remaining forest distributed? Implications for conservation. Biol Conserv 142: 1141-1153.

RICHARDS PW. 1996. The Tropical Rain Forest: an ecological study. Cambridge: Cambridge University Press. $2^{\text {nd }}$ ed., $575 \mathrm{p}$.

RODRIGUES ASL AND BROOKS TM. 2007. Shortcuts for biodiversity conservation planning: the effectiveness of surrogates. Annu Rev Ecol Evol Syst 38: 713-737.

SIQUEIRA MF AND PETERSON AT. 2003. Consequences of global climate change for geographic distributions of Cerrado tree apecies. Biota Neotrop 3: 1-14.

STANTON JC, SHOEMAKER KT, PEARSON RG AND AKÇAKAYA HR. 2014. Warning times for species extinctions due to climate change. Glob Chang Biol 21: 1066-1077.

STOCKWELL D AND PETERS D. 1999. The GARP modelling system: problems and solutions to automated spatial prediction. Int J Geogr Inf Sci 13: 143-158.

TESSAROLO G, RANGEL TF, ARAÚJO MB AND HORTAL J. 2014. Uncertainty associated with survey design in Species Distribution Models. Divers Distrib 20: 1258-1269.

THERNEAU ATM, ATKINSON B, RIPLEY B AND RIPLEY MB. 2011. Package "rpart". Computer program.

TSOAR A, ALLOUCHE O, STEINITZ O, ROTEM D AND KADMON R. 2007. A comparative evaluation of presence-only methods for modelling species distributions. Divers Distrib 13: 397-405. 